\title{
Pixels per Centimeter
}

National Cancer Institute

\section{Source}

National Cancer Institute. Pixels per Centimeter. NCI Thesaurus. Code C114238.

A unit of image resolution expressed in the numbers of pixels per centimeter in the horizontal or vertical direction. 